\title{
Entrepreneurship opportunities in horticulture sector
}

\author{
Rajesh Lather*, Vandana, Sridevi and Gurnam Singh \\ Chaudhary Charan Singh Haryana Agricultural University, Hisar (Haryana) India \\ (Email: rajeshlather@hau.ac.in)
}

\begin{abstract}
Horticulture sector has the potential to enhance the farm income, provide livelihood security and earn foreign exchange. However, focused policy interventions are needed to realise the potential of this sector. India is the second largest producer of fruits and vegetables globally. During 2019-20, the production of fruits is 102.03 million MT and that of vegetables is 189 million MT and that of flowers is 2.94 million MT. The salient features of commercial horticulture are perishability, intense technology, high profitability accompanied with high investment and high risks including vulnerability to post-harvest losses. Overall, it demands very good entrepreneurship and leadership.The review reveals the trends of the horticultural sector in India and identifies the growth prospects. According to the Economic Survey 2020-202, the share of agriculture in gross domestic product (GDP) has reached almost 20 per cent for the first time in the last 17 years, making it the sole bright spot in GDP performance during 2020-21. The resilience of the farming community in the face of adversities made agriculture the only sector to have clocked a positive growth of 3.4 per cent at constant prices in 2020-21, when other sectors slid. The share of agriculture in GDP increased to 19.9 per cent in 2020-21 from 17.8 per cent in 2019-20. The Horticulture has become a key driver for economic development in many of the states in the country and it contributes 30.4 per cent to GDP of agriculture, which calls for technology-led development. The research priorities are for genetic resource enhancement and its utilization, enhancing the efficiency of production and reducing the losses in environment friendly manner. Horticultural sector accounts for about $37 \%$ of the total exports of agricultural commodities, and the exports have recorded sustained rising trend. The major concerns of the sector are improving the productivity through research and development, enhancing the share of value-added products, geographical diversification of exports and enhancing the infrastructure including cold storage and rural roads. The horticulture sector has been considered as the sun rising sector of Indian agriculture because of its contribution to livelihood and nutritional security. Here are some strategic options to overcome the hurdles in the entrepreneurship climate setting process to enhance farmers' income.
\end{abstract}

Key Words : Entrepreneurship, Diversification, Livelihood, GDP, Value added product, Post-harvest losses

View Point Article : Lather, Rajesh, Vandana, Sridevi and Singh, Gurnam (2021). Entrepreneurship opportunities in horticulture sector. Internat. J. agric. Sci., 17 (AAEBSSD) : 311-318, DOI:10.15740/HAS/IJAS/17-AAEBSSD/311-318. Copyright@2021: Hind AgriHorticultural Society.

Article History : Received : 05.07.2021; Accepted : 08.07.2021

\section{INTRODUCTION}

Keeping in mind, the great potential and role of the horticulture sector in increasing farmer's income, the Government of India has allocated Rs. 2250 crores during 2021-22 for promotion and for holistic growth and development of the horticulture sector covering fruits, vegetables, root and tuber crops, mushrooms, spices, flowers, aromatic plants, coconut, cashew and cocoa in the country under Integrated Development of Horticulture. The government intervention in horticulture sector has led to the situation wherein horticulture

\footnotetext{
*Author for correspondence:
} 
production has surpassed the agriculture production in the country. According to National Horticulture Board database, during the year 2019-20, the country recorded its highest ever horticulture production of 320.77 million tonnes from an area of 25.66 million hectares. As per the 1st Advance Estimates for 2020-21 the total horticulture production in the country is 326.58 lakh million tonnes from an area of 27.17 million ha. The increase in production of fruits, vegetables, flowers, and spices were witnessed, whereas a decrease in plantation crops, and aromatics and medicinal plants was registered over FY19.It has not only resulted in India's self-sufficiency in the horticulture sector but also contributed towards achieving sustainable development goals of zero hunger, good health and wellbeing, no poverty, gender equality etc.Among the high value crops in India, horticultural crops command high value not only in terms of their potential in generating income and employment, but also on the basis of export-earning opportunities. With the changing consumption pattern towards horticultural crops and rising per capita income, there is an increase in internal demand as well as export opportunities for horticulturalcrops.Diversification towards horticultural crops is expounded as the strength of Indian agriculture due to its potential to produce a wide variety of horticultural crops under varied agro-climatic conditions. The cultivation of horticultural crops is labour intensive and requires a significantly higher labour force, starting from the stage of planting the trees, to the point of its marketing. Thus, horticulture sector has a potential to absorb and employ huge chunk of unemployed population in the country.

India has witnessed the modernization of horticultural revolution over the last few decades due to the integration of the Global Positioning System, Remote Sensing Technology, along with Geographic Information System. Remote sensing technology like orchard rejuvenation, crop identification, aqua horticulture soil health mapping, crop intensification, land resource mapping and crop yield estimation would assist the farmers in growing their horticulture crops along with riding on the chariot of profitability. In horticultural crops, post-harvest losses are generally high, ranging from 15 to 50 per cent. A high wastage and loss of output has been witnessed, especially in the hilly districts due to lack of initiatives on part of the farmers to market the fruits. Such wastage not only results in loss of revenue but also reduce the per capita availability of fruits.As per the official records, around 7, 00,000 families involved in the farming domain are somehow connected with the horticulture sector in India.In the present situation, farmers are required to develop themselves as entrepreneurs for deriving greater benefits from horticulture. The marketed surplus will remain small, keeping in view the holdings acquired by the farmers in thecountry. Small farmers having small surplus, appeared to be reluctant in marketing their produce, as the net returns, they could attain would not cover even the cost of marketing.

The new generation of educated farmers and unemployed rural youth have an opportunity to become entrepreneur and adopt horticulture as a business enterprise. A farmer does not become an entrepreneur only by adopting new agricultural technology but becomes an entrepreneur by working as an operator of farm business. The marketing cost of fruits and vegetables is almost $50 \%$ of the total cost of production which tends to be increased further with more wastage and loss of produce. 'Assembling' is a marketing function that can solve this problem in horticultural marketing, but we need entrepreneurs who can manage and save the resources for themselves and for the country. There is a long term need to remove the distortions in the present supply chain and create better integration between different links of the supply chain. Entrepreneurship development among farmers is an important way of achieving that integration for bringing net gain to producers, consumers and to the nation.

\section{Entrepreneurship opportunities:}

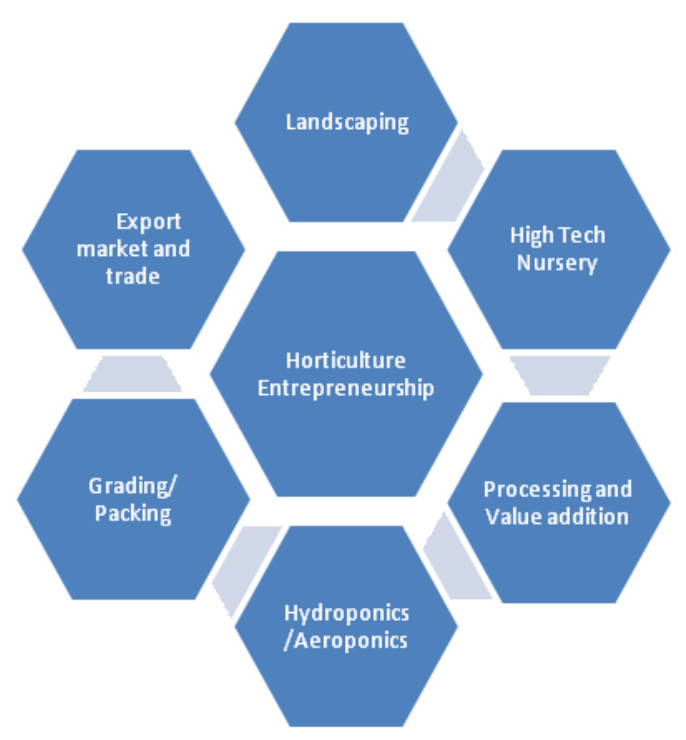




\section{High- tech nursery:}

Agriculture is the backbone of our country and has a prime role in Indian economy. Agricultural sector provides livelihood to more than 65 percent of the labour force. Under agriculture sector horticultural crops play very important role to economy (Meena et al., 2013; Meena et al., 2016). It ranks second in fruits and vegetables production in the world, after China. India, in the recent years, has emerged as a leading producer of horticultural produce at global level. The productivity of banana, grapes papaya and several vegetables in India is higher than rest of the world. In order to maintain the leadership role, the regular supply of good planting material is important for the horticultural growth in the country. Massive area expansion programmes under National Horticulture Mission and Technology Mission for development of horticulture in North Eastern States and Himalayan states require improved varieties for replanting, planting in marginal and arid areas etc. At present, hardly $30-40 \%$ of the demand for quality planting material in different horticultural crops is being met by the existing infrastructure in public domain. Hence, all farmers do not have access to elite certified planting material that leads to low productivity and quality of the produce. The horticulture sector is being looked as a harbinger of ensuring nutritional security,providing sustainable income to the farmers and entrepreneurer, generating employment, empowering the farm women and earning the valuable foreign exchange through exports. The prime need in the current scenario is the establishment of good and high-tech nursery to make available planting material of the highest possible quality for new development areas and replanting. Poor planting materials lead to low yield and unnecessary cost.

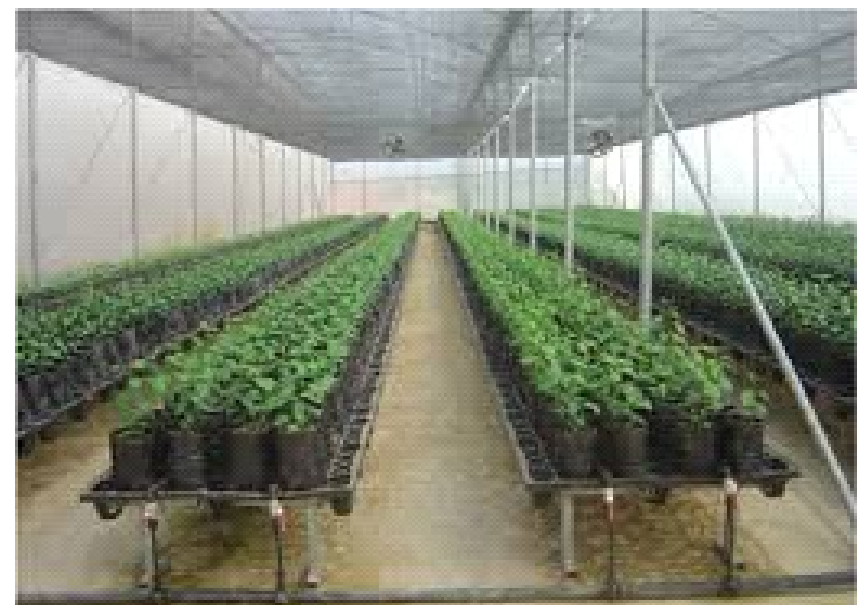

Horticulturalists use modern nurseries for the production of seedlings and mother plants. These plants are propagated through different methods such as seeds, inarching, budding, veneer grafting, patch budding and soft wood grafting. Nurseries have great demand for the production of plants, bulbs, rhizomes, suckers and grafts. But in general, good quality and assured planting material at reasonable price is not available. So, persons having a skill of propagation of plants can go for this avenue as an entrepreneurship of future. The hightechnurseries are well equipped with infrastructure, manpower, automation and target to produce seedling/ propagules of horticultural crops. The nursery is pre requisite for meeting the quality seedlings demand and nursery management is a potential tool to execute the activity in successful way (Krishnan et al., 2014).

\section{Peri urban horticulture/ Landscaping:}

The United Nations has projected that over twothird of the world's population will be living in cities by 2050 , the current global population is 7.7 billion, and in most parts of the world, the current urban population is increasing three times faster than the rural population. People migrate to urban areas with the hope of a better living, considering relatively better infrastructural facilities, and higher per capita income. As cities grow, urban areas expand geographically, characterized by impervious surfaces like roads, pavements and buildings which lead to high density living and decreasing green spaces threatening the living conditions of the urban areas. These conditions drastically changed in the recent past with the increase in temperatures and vehicular pollutants devoiding the natural systems in the cities (Ramachandra et al., 2015). The scarcity of the natural

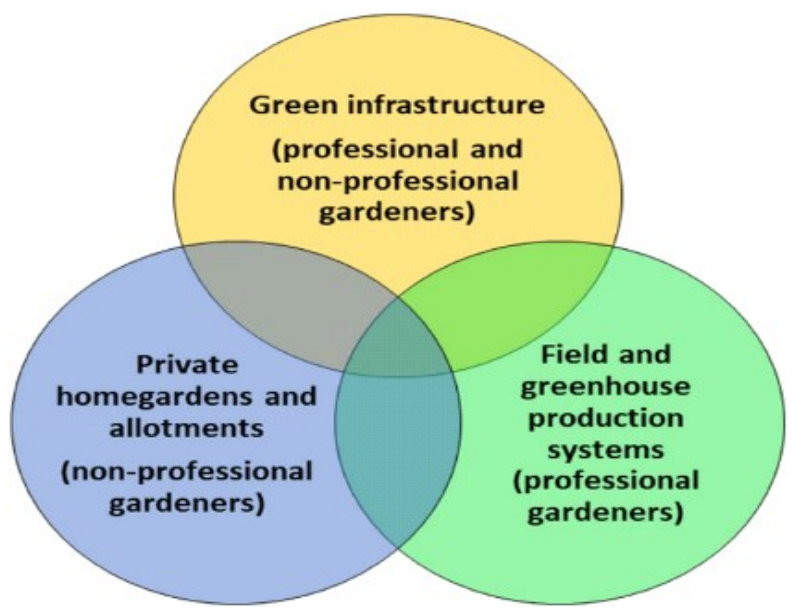


resources such as water, fresh air and green spaces at one hand and the rapidly depleting resources at the other hand, the process of sustainable development and creating urban green infrastructure is becoming a challenging task for Indian cities.

Rapid urbanization in India is accompanied by a rapid increase in urban poverty and urban food insecurity which is further worsened by food inflation leaving a lot of underprivileged urban population with no or low-quality food. The major factors influencing the urban environment such as climate, water resources and air quality and other multi folded issues can be addressed through setting up of green infrastructure at various scales. The recent trend in the changing perspectives of landscape planning in Indian cities and addressing the loss of natural infrastructure in the cities has to be balanced by creating adaptable built environment with green infrastructure such as peri-urban farms, urban forests and community farms in urban spaces as part of existing and evolving city fabric. To overcome these challenges, Peri-Urban horticulture can a be part of a solution where the urban residents can produce food, flowers, medicinal plants, ornamental plants, herbs, shrubs etc by using resources such as organic waste for compost and waste water for irrigation and serve the produce to the local markets.

The practice of peri-urban horticulture promotes economic development through food production, builds social capital, community well-being and civic engagement. Community gardens, farms in city blocks, vertical farms based on hydroponics or aeroponics and aquaculture are some smart peri-urbanhorticulture models. Peri-urban horticulture can be a sustainable strategy to reduce urban poverty, food insecurity and enhance urban environmental management. It contributes to poverty alleviation, social inclusion of the poor, women empowerment, productive use of vacant plots and reuse of urban waste. Consumers, especially the urban poor, will be able to enjoy the access to fresh produce at better prices. A few Initiatives such as composting and vermiculture, horticultural activities and terrace farming are being witnessed in small pockets in Indian cities, including Chandigarh, Gurugram, Kolkata, Chennai, Delhi, Mumbai, Bangalore and Hyderabad. According to the UN's Food and Agriculture Organization (FAO, 2013), in developing countries, $10-30 \%$ of produce is spoiled during transit which can be reduced upto some extent by peri-urban horticulture.

\section{Hydroponics/ aeroponics:}

Hydroponics, a subset of horticulture, is a growing plant without soil, using mineral nutrient solutions in a water solvent. Hydroponics can be briefly defined as cultivation of plants without soil (Savvas, 2017). According to the most recent report, it is expected to reach a world growth rate of $18.8 \%$ from 2017- 2023, corresponding to a global hydroponic market of 490.50 millionUSD by 2023. According to growers continuous production is possible only through hydroponic systems i.e, production round the year and in a short growing period, requires less space, and plants can be produced anywhere, i.e., in a small spaces with a controlled growth environment (Hughes, 2017). Factors like depleting water resources, gradually decreasing land under cultivation and reducing infertility of the soil, etc., are raising the need to invent innovative and fruitful cultivation methods. Moreover, with hydroponics, there is a better opportunity to place the fresh produces in the market since their average nutritional quality and consumer's acceptance are higher (Mehra et al., 2017). Hydroponics is one such revolutionary method of farming. India Hydroponics Market is segmented by technology (Nutrient Film Technique, Drip System, Ebb and Flow/ Flood and Drain System (Table 1), by type (Outdoor Farming, Indoor Farming), by produce type (fruits and vegetables liketomato, strawberry, bell pepper, leafy vegetables, cucumber, flowers etc) and by region (Andhra Pradesh, Telangana, Gujarat, Haryana, Maharashtra).

India's hydroponics market is experiencing the establishment of new commercial plants in tier 1 cites in collaboration between regional producers and global technology providers to meet the growing demand for exotic and organic foods.
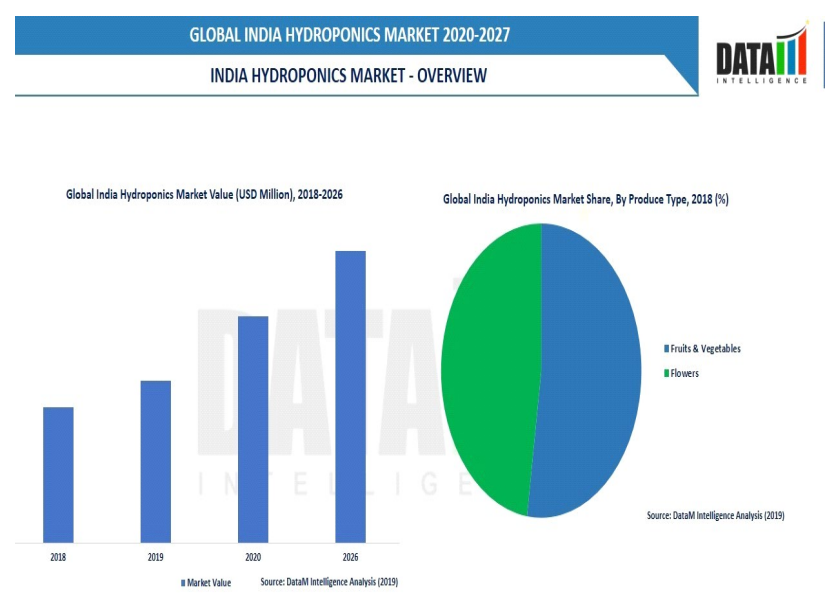
Entrepreneurship opportunities in horticulture sector

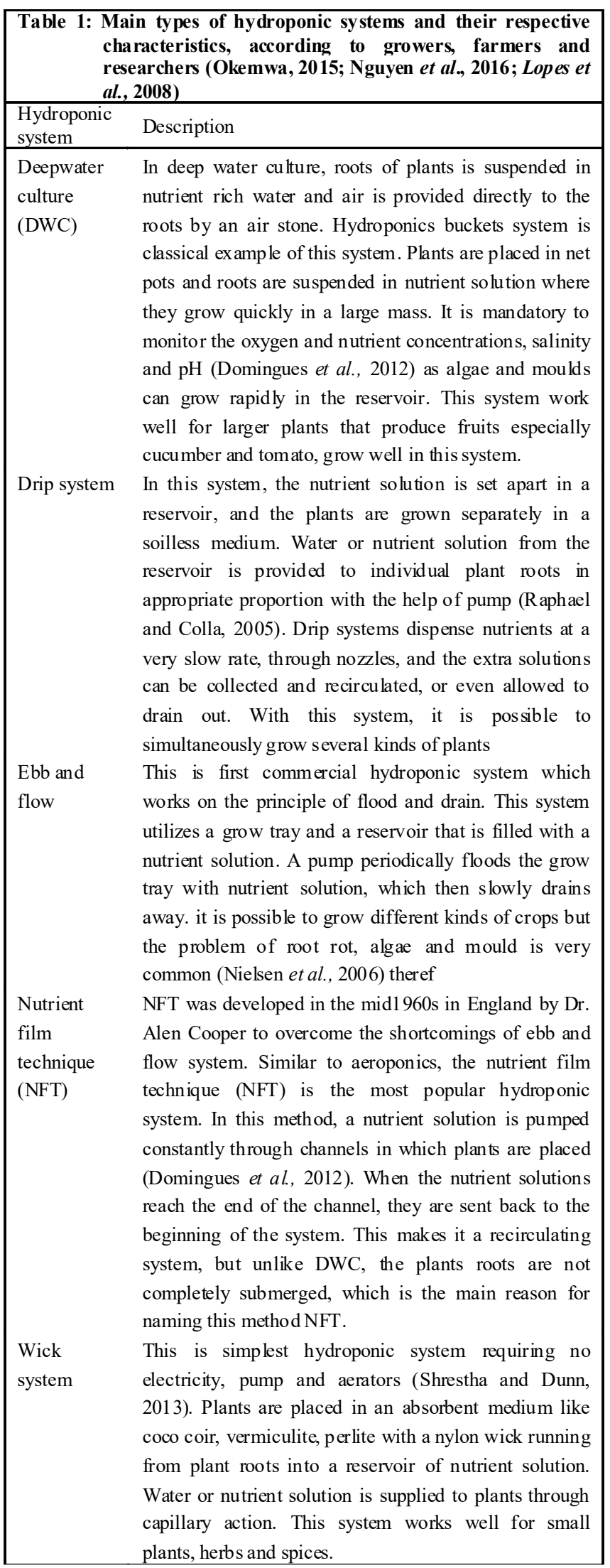

Growing demand for sustainable and protected farming practices and higher yield of crops grown under hydroponic facilities over traditional farming are the driving factors for its growth. According to the study published by V.Chandrshekaran, a founder of a hydroponics technology company, the average yield of lettuce per acre yearly was recorded between 9-10 tons in soil-based agriculture and 300-400 tons in hydroponics agriculture.(Table 2) Increased hydroponics' investment rate over the traditional soil-based agricultural process through increased yield and minimal water cultivation might further boost the agricultural communities towards adopting the hydroponics technologies during the forecast period.

\begin{tabular}{|c|c|c|}
\hline \multicolumn{3}{|l|}{ Table 2} \\
\hline Vegetable type & $\begin{array}{c}\text { Soil agriculture avg } \\
\text { yield per acre }\end{array}$ & $\begin{array}{c}\text { Hydroponics agriculture } \\
\text { avg yield per acre }\end{array}$ \\
\hline Lettuce & $9-10$ tons & $300-400$ tons \\
\hline Strawberries & $20-25$ tons & 50 tons \\
\hline Cucumber & $15-20$ tons & 200 tons \\
\hline Tomato & $10-12$ tons & $180-200$ tons \\
\hline Bell Pepper & $10-12$ tons & $120-140$ tons \\
\hline Potato & $8-10$ tons & $60-70$ tons \\
\hline Cabbage & 6-7 tons & $10-12$ tons \\
\hline
\end{tabular}

\section{Processing and value addition:}

During the year 2019-20, the country recorded its highest ever horticulture production of 320.77 million tonnes from an area of 25.66 million hectares. As per the $1^{\text {st }}$ Advance Estimates for 2020-21 the total horticulture production in the country is 326.58 lakh million tonnes from an area of 27.17 million ha. Increase in production of fruits, vegetables, flowers, and spices were witnessed, whereas a decrease in plantation crops, and aromatics and medicinal plants was registered over FY19. Therefore, there is a vast scope of export of fresh and processed products from the country. Fruit and vegetable processing market is growing at a growth rate of $7.95 \%$ in the forecast period of 2020-2027 due to spreading health consciousness among consumers and the increasing vegetarian population drive the demand for the processed products of fruits and vegetables. The processing of fruits and vegetables is very important before direct consumption. The main aim of the processing is to retain the colour, taste, texture and nutrition besides the improvement in the shelf life of perishable fruits and vegetables. 
The horticultural crops, because of their high moisture content are inherently more liable to deteriorate especially under sub-tropical and tropical conditions. Moreover, they are biologically active and carry out respiration and other biochemical activities, which deteriorate the quality of the produce. Hence, it becomes imperative to check the quality after harvest because 25- 50 per cent losses occur due to improper handling and storage. The losses also occur because of poor facilities, lack of knowhow, poor management and market dysfunction. Proper storage condition, temperature and humidity are required to extend the shelf life and maintain the quality. The extent of processing in the country is only 2.2 per cent which needs to be increased to 10.0 per cent in the near future. The major processed items in this segment are fruit pulps and juices, fruit based ready-to-serve beverages, canned fruits and vegetables, jams, squashes, pickles, chutneys and dehydrated vegetables. The new arrivals in this segment are vegetable curries in retortable pouches, canned mushroom and mushroom products, dried fruits and vegetables and fruit juice concentrates.

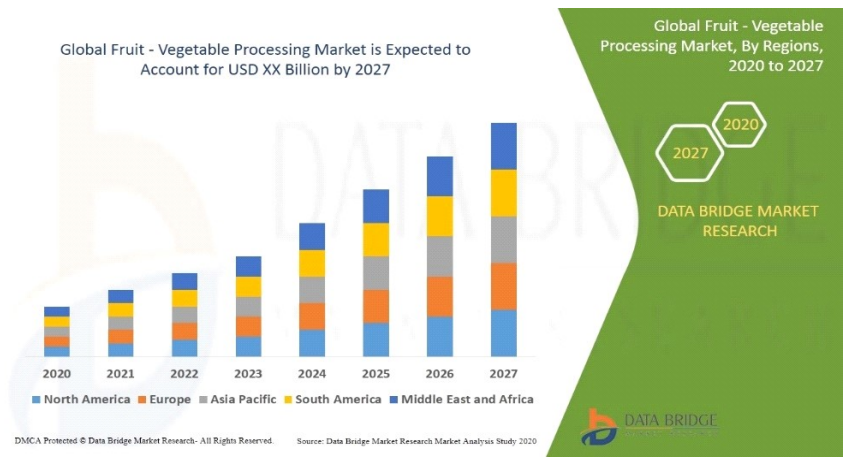

Due to the mature fruit and vegetable processing industry and the involvement of major corporations, North America is expected to hold the largest share of the fruit and vegetable processing market. India is projected to be the fastest-growing market in the Asia Pacific region during the forecast period. The evolving lifestyles and tastes, increased awareness of the benefits of processed fruits and vegetables, the increasing health-conscious population, higher disposable incomes and the growth of the middle-class population are some of the factors that drive fruit and vegetable processing market growth in the region. According to the World Bank figures, about $37 \%$ of the fruit and vegetables that are traded internationally (by value) are processed products which are largely due to the non-perishable nature of processed produce relative to fresh produce (IBISWorld, 2015).

\section{Grading and packaging:}

Horticulture produce particularly fruit and vegetable form an important part of trade both nationally and internationally. The rural unemployed youth may opt this post- harvest management step as an entrepreneurship. Among the post-harvest operations applied during handling of fruits and vegetables, grading and packaging plays an important role to remove undesirable or foreign matters from the harvested crops into various fractions and for proper handling of the produce. The shrivelled, damaged and rotten materials generally result in lower prices. Thus, systematic grading is pre-requisite for efficient marketing of fruits and vegetables. Grading is sorting or categorisation of fruits and vegetables into different grades according to the size, shape, colour, and volume to fetch high price in market. Besides grading, the other post-harvest operation is selection of packaging material and design of package is also critical to marketing success. Quality loss is the result of improper handling and transportation in marketing of produce (Kumar et al., 2015). Produce kept within sealed packages resulted in an atmosphere with high $\mathrm{CO}_{2}$ and low $\mathrm{O}_{2}$ content. These conditions retained firmness, low acidity and soluble solids concentration and delayed fruit ripening and thus shelf life can be improved (Sabir and Agar, 2011).

Directorate of Marketing and Inspection (DMI) under Ministry of Agriculture and Farmers Welfare, Government of India was set up to frame the grade standards in a scientific manner. The different grades used in some important fruits and vegetables with respect to weight, diameter or length as applicable are given as under.

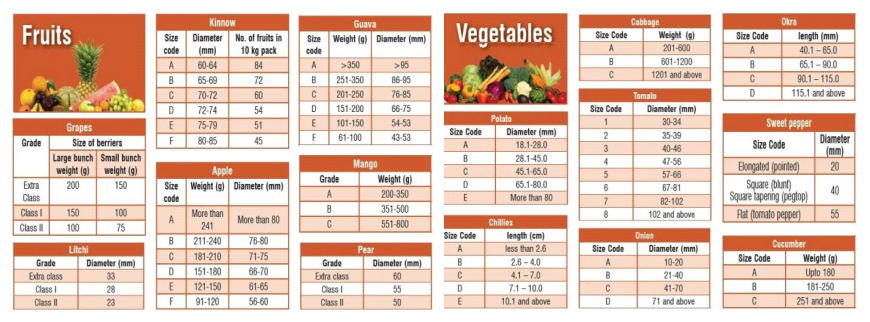

\section{Export market and trade:}

According to FAO (2019), India is the second largest producer of fruits and vegetables and ranks second in production of potatoes, onions, cauliflowers, 
brinjal, cabbages, etc. Amongst fruits, the country ranks first in production of bananas $(26.08 \%)$, papayas (44.05\%) and mangoes (including mangosteens and guavas) $(45.89 \%)$. The vast production base offers India tremendous opportunities for export. During 2019-20, India exported fruits and vegetables worth Rs. 9,182.88 crores which comprised of fruits worth Rs. 4,832.81 crores and vegetables worth Rs. 4,350.13 crores. The major destinations for Indian fruits and vegetables are Bangladesh, UAE, Netherland, Nepal, Malaysia, UK, Sri Lanka, Oman and Qatar. The grapes, pomegranates, mangoes, bananas, oranges and their processed products account for larger portion of fruits exported from the country while onions, mixed vegetables, potatoes, tomatoes, and green chilly contribute largely to the vegetable export basket. Recently, the export of fruits and vegetables from India is slowly gaining pace. This has occurred due to concurrent developments in the areas of cold chain infrastructure, increase in productivity and quality through research, modern post-harvest technologies, favourable government policies and various initiatives taken by APEDA.

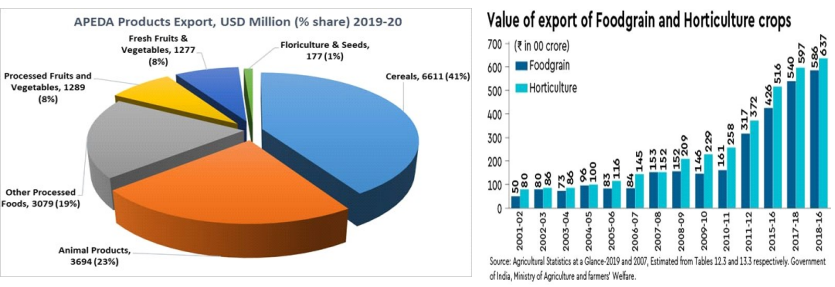

\section{The major challenges:}

The horticulture sector is still facing a lot of challenges in terms of gap in production technology, high post-harvest loss and gaps in post-harvest management, poor transport and supply chain infrastructure. There is tremendous scope for enhancing the productivity of Indian horticulture which is imperative to cater to the country's estimated demand of 650 million tonnes of fruits and vegetables by the year 2050 .

\section{Suggestions:}

Some of the new initiatives like research and development matching pace with the latest technologies and innovations, focus on elite planting material production, cluster development programme, hydroponics and aeroponics, credit push through Agri Infra Fund, ease access to government schemes and policies related to processing and value addition, cold supply chain management, formation and promotion of FPOs are the right steps in this direction.

\section{REFERENCES}

Domingues, D.S., Takahashi, H.W., Camara, C.A.P. and Nixdorf, S.L. (2012). Automated system developed to control $\mathrm{pH}$ and concentration of nutrient solution evaluated in hydroponic lettuce production. Computers and Electronics in Agriculture, 84: 53-61.

FAO, (2013). Food Wastage Footprint: Impacts on Natural Resources (Summary Report). 1-63.

Hughes, A.J. (2017). Hydroponic Growing Offers Advantages, but won't replace the soil.

IBIS World, (2015). Global fruit and vegetables processing. IBIS World Industry Report, September 2015. wwwibisworld com (Accessed on October 122015.

Krishnan, P.R., Kalia, R.K., Tewari, J.C. and Roy, M.M. (2014). Plant Nursery Management and Plant Nursery Management: Principles and Practices, Central Arid Zone Research Institute, Jodhpur, 40pp.

Kumar, V., Shankar, R. and Kumar, G. (2015). Strategies used for reducing postharvest losses in fruits \& vegetables. Int. $J$. Sci. Eng. Res., 6:130- 137.

Lopes, D.L.G., Petter, M. S., Manfron, P., Borcioni, E., Muller, L., Dischkaln, D. A. A. and Pereira, M. K. (2008). Consumo de energia elétrica e produção de alface hidropônica com três intervalos entre irrigações. Ciência Rural., 38:815-818.

Meena, L.K., Sen, C. and Bairwa, S.L., Jhajharia and Raghuwanshi, N.K. (2013). Economics of garlic production in Baran district of Rajasthan; Break Even Analysis, Asian Journal of Agriculture and Rural Development, 3(10): 697 701.

Meena, L.K., Bairwa, S.L., Kumari, M and Wadhwani, M.K. (2016). Performance of Onion in Bihar - An economic analysis, Economic Affairs, 61(2): 299-304.

Mehra, S., Leng, T.W. and Yamashita, Y. (2017). Are Singaporeans Ready for Hydroponics.

National horticulture board database (2019). Ministry of agriculture, Government of India, www.nhb.gov.

Nguyen, N.T., Mcinturf, S.A., Mendozacózatl, D.G. (2016). Hydroponics: A versatile system to study nutrient allocation and plant responses to nutrient availability and exposure to toxic elements. Journal of Visualized Experiments, 10: 379154317.

Nielsen, C.J., Ferrin, D.M. and Stanghellini, M.E. (2006). Efficacy of biosurfactants in the management of Phytophthora capsici on pepper in recirculating hydroponic systems. 
Rajesh Lather, Vandana, Sridevi and Gurnam Singh

Canadian Journal of Plant Pathology, 28(3): 450-460.

Okemwa, E. (2015). Effectiveness of aquaponic and hydroponic gardening to traditional gardening. International Journal of Scientific Research and Innovative Technology, 2:2313-3759.

Ramachandra, T.V.,Aithal, Bharath, H. and Sreejith, K. (2015). GHG footprint of major cities in India, Renewable and Sustainable Energy Reviews, Elsevier, 44(C): 473-495.

Rouphael, Y. and Colla, G. (2005). Growth, yield, fruit quality and nutrient uptake of hydroponically cultivated zucchini squash as affected by irrigation systems and growing seasons.
Scientia Horticulturae, 105 (2): 177-195.

Sabir, F.K. and Agar, T. (2011). Effects of 1methylcyclopropene and modified atmosphere packing on postharvest life and quality in tomatoes. J. Food Qual., 34:111-118.

Sarah, W.S. (2017). Hydroponics-vs-soil reasons why hydroponics is better than soil.

Shrestha, A. and Dunn, B. (2013). Hydroponics. Oklahoma Cooperative Extension Services.

$17^{\text {th }}$ Year

$\star \star \star \star \star$ of Excellence $\star \star \star \star \star$ 